\title{
Macroeconometric Modelling with a Global Perspective
}

\author{
M. Hasham Pesaran and Ron Smith
}

February 2006

CWPE 0604

Not to be quoted without permission 


\title{
Macroeconometric Modelling with a Global Perspective*
}

\author{
M. Hashem Pesaran \\ Ron Smith \\ Cambridge University and USC Birkbeck College, London
}

January 2006

\begin{abstract}
This paper provides a synthesis and further development of a global modelling approach introduced in Pesaran, Schuermann and Weiner (2004), where country specific models in the form of VARX* structures are estimated relating a vector of domestic variables, $\mathbf{x}_{i t}$, to their foreign counterparts, $\mathbf{x}_{i t}^{*}$, and then consistently combined to form a Global VAR (GVAR). It is shown that the VARX* models can be derived as the solution to a dynamic stochastic general equilibrium (DSGE) model where over-identifying long-run theoretical relations can be tested and imposed if acceptable. This gives the system a transparent long-run theoretical structure. Similarly, short-run over-identifying theoretical restrictions can be tested and imposed if accepted. Alternatively, if one has less confidence in the short-run theory the dynamics can be left unrestricted. The assumption of the weak exogeneity of the foreign variables for the long-run parameters can be tested, where $\mathbf{x}_{i t}^{*}$ variables can be interpreted as proxies for global factors. Rather than using deviations from ad hoc statistical trends, the equilibrium values of the variables reflecting the long-run theory embodied in the model can be calculated. This approach has been used in a wide variety of contexts and for a wide variety of purposes. The paper also provides some new results.
\end{abstract}

Keywords: Global VAR (GVAR), DSGE models, VARX*.

JEL Classification: C32, E17, F37, F42.

${ }^{*}$ This paper benefited from comments at the MMF 2005 Conference in Crete and from Til Schuermann and the help of Vanessa Smith. 


\section{Introduction}

International economic interdependence means that national economic issues have to be considered from a global perspective. But most national econometric models do not have a coherent global dimension and allowance for interdependencies has to be done in an informal off-model way, which casts doubt on the plausibility of the results. Over the last 25 years, Vector Autoregressions, VARs, have displaced large national macroeconometric models as the principal tool academic economists have used for forecasting, policy analysis and evaluating theories, e.g. consistency with impulse response functions from VARs is a common criterion for judging the empirical adequacy of theoretical models. Large national econometric models are still used by policy-makers and others who need to model the interaction between a large number of variables but by few academics. VARs have the advantage that the reduced form can be estimated and coherent long-run properties that are consistent with the theory can be tested and if accepted imposed as cointegrating vectors. The cointegration may be between different variables in the same country, the situation often considered, but it may also involve variables in different countries. Most long run relations, such as the purchasing power parity (PPP), or the uncovered interest parity (UIP), are between variables in a given country and in the rest of the world. We refer to foreign variables as * variables, and we extend the VAR to a $\mathrm{VARX}^{*}$, treating the foreign variables as weakly exogeneous or long-run forcing for the parameters of the conditional model.

The principal disadvantage of VARs is that they can only deal with a relatively small number of variables. The dominant response to this problem, established in the US, is to adopt a closed economy model focussing on half a dozen domestic variables. But this is unsatisfactory since all macroeconomics is now open economy macroeconomics. Macroeconomic policy analysis or risk management whether by governments, banks, multinational firms or international financial institutions, requires taking account of the increasing interdependencies that exist across countries. This invariably means dealing with very high dimensional systems. The GVAR approach advanced in Pesaran, Schuermann and Weiner (2004, PSW) provides a simple solution where country specific models in the form of VARX* structures are estimated relating a vector of domestic variables, $\mathbf{x}_{i t}$, to their foreign counterparts, $\mathbf{x}_{i t}^{*}$, and are then consistently combined to form a Global VAR (GVAR). The high dimensional nature of the model is circumvented at the estimation stage by constructing the country specific foreign variables, $\mathbf{x}_{i t}^{*}$, using predetermined coefficients such as trade weights, and by noting that for relatively small open economies $\mathbf{x}_{i t}^{*}$ can be treated as weakly exogenous (or forcing) for the long run relations. The model for the US economy is treated differently due to the dominant role that the US plays in the world economy. The GVAR (also affectionately known as the Gigantic VAR!) allows for interdependence at a variety of levels in a transparent way that can be empirically evaluated and have long-run relationships consistent with the theory and short run relationships that are consistent with the data.

The present paper provides an overview of the GVAR and shows how the 
underlying country specific VARX* modules can be derived from Dynamic Stochastic General Equilibrium (DSGE) models. It is common to present a spectrum with theory consistent DSGE models at one extreme and atheoretical VARs at the other extreme. However, it is possible to put a lot of theory into the VAR, where it may be tested; and it is common to ignore a lot of theory in the estimation of DSGE model by using deviations from an ad hoc trend as data. In addition, the theory may ignore important factors: the representative agent approach ignoring heterogeneity and aggregation; the rational expectations approach ignoring learning. Thus it is important that the theory be tested before it is used.

This paper draws on a variety of work. The original work on a long run structural model for the UK economy was in Garratt, Lee, Pesaran and Shin (2003a). This model was used for assessing forecasting uncertainty in Garratt, Lee, Pesaran and Shin (2003b) and the details of the approach are set out in a forthcoming volume by Garratt, Lee, Pesaran and Shin (2006, GLPS). This model is used to analyse credit risk in Pesaran, Schuermann, Treutler and Weiner (2005), and Pesaran Schuermann, and Treutler (2005). A more recent extended and updated version of the GVAR, which treats the Euro area as a single unit is in Dees, di Mauro, Pesaran and Smith (2005, DdPS). This model is used to evaluate UK entry into the Euro in Pesaran, Smith and Smith (2005). The factor model approach is developed in Pesaran (2004) and discussed further in Breitung and Pesaran (2005).

We begin with a standard theoretical DSGE macro-model and show that the solution to this model has a VARX* structure. We then examine the econometric issues associated with using a VARX* structure for national modelling in a global context. Then we put the sets of VARX* models together in a Global VAR, GVAR; and present some new empirical results obtained using the DdPS GVAR. Finally we examine the relationship of this approach to that using unobserved common factors.

\section{A Small Open Economy New Keynesian Model}

\subsection{The Model}

The standard model in macroeconomics is a three equation DSGE system which can be derived from the optimising decisions of a representative agent with staggered pricing or wage setting with both forward and backward looking inflation components. This model is normally derived in a closed economy setting, but Gali and Monacelli (2005), among others, develop a small open-economy version. Consider a particular economy denoted $i$. The first equation of the system is a New Keynesian Phillips Curve (NKPC) explaining inflation, $\pi_{i t}$, by the deviation of $\log$ output from its natural level, $\widetilde{y}_{i t}=\left(y_{i t}-\bar{y}_{i t}\right)$; the second is an optimising IS curve, explaining the output gap, by the real interest rate

$\left(r_{i t}-E_{t} \pi_{i, t+1}\right)$ and the third is a Taylor rule, describing the determination of the short interest rate, $r_{i t}$, in response to inflation, the output gap and expected 
foreign inflation. A canonical version is given by

$$
\begin{aligned}
\pi_{i t} & =a_{i \pi}+\lambda_{i \pi} \pi_{i, t-1}+\left(1-\lambda_{i \pi}\right) E_{t} \pi_{i, t+1}+\gamma_{i \pi} \widetilde{y}_{i t}+\varepsilon_{i, \pi t}, \\
\widetilde{y}_{i t} & =a_{i y}+\lambda_{i y} \widetilde{y}_{i, t-1}+\left(1-\lambda_{i y}\right) E_{t} \widetilde{y}_{i, t+1}-\gamma_{i y}\left(r_{i t}-E_{t} \pi_{i, t+1}\right)+\varepsilon_{i, y t}, \\
r_{i t} & =a_{i r}+\rho_{i r} r_{i, t-1}+\rho_{i \pi} \pi_{i t}+\rho_{i y} \widetilde{y}_{i t}+\lambda_{i r} E_{t} \pi_{i, t+1}^{*}+\varepsilon_{i, r t},
\end{aligned}
$$

where $\varepsilon_{i, \pi t}$ is interpreted as a cost shock, $\varepsilon_{i, y t}$ a preference or technology shock and $\varepsilon_{i, r t}$ a policy shock.

Gali and Monacelli (2005) use domestic prices rather than the usual CPI which has a foreign component (which could be allowed for in the Phillips curve). They have a standard NKPC, with domestic inflation a function of expected domestic inflation (with a coefficient equal to the discount rate) and marginal cost. Marginal cost depends on domestic and foreign output, the terms of trade and productivity. The terms of trade can be made a function of domestic and foreign output and the natural level of output a function of productivity and foreign output. Thus the output gap can replace marginal cost in the NKPC. The natural real rate of interest is variable, a function of productivity and the expected growth rate of foreign output. However, if productivity has a unit root, it is just a function of expected foreign output growth. They discuss whether it is better to target domestic inflation or CPI inflation (which would reflect foreign prices) and argue the former is better. Including foreign prices in the Taylor Rule, in the equation above, allows domestic prices to be targeted, in which case $\lambda_{i r}$ would have a negative coefficient determined by the degree of openness.

Typically the natural level of output is proxied by a linear time trend, or is modelled as an unobserved component. In the Gali and Monacelli (2005) model, the natural level of output depends on productivity and foreign output, $y_{i t}^{*}$, which could be a country specific measure. However, given international dissemination of technology, productivity itself would be a function of foreign output. Thus an alternative measure of the output gap would be

$$
\widetilde{y}_{i t}=y_{i t}-y_{i t}^{*},
$$

which we will use.

Consider the three equation system above, using foreign output as a proxy for the natural level of output. Define $\mathbf{x}_{i t}=\left(\pi_{i t}, y_{i t}, r_{i t}\right)^{\prime}, \mathbf{x}_{i t}^{*}=\left(y_{i t}^{*}, \pi_{i t}^{*}\right)^{\prime}$, and $\varepsilon_{i t}=\left(\varepsilon_{i, \pi t}, \varepsilon_{i, y t}, \varepsilon_{i, r t}\right)^{\prime}$, then (1) can be written

$$
\begin{aligned}
\mathbf{A}_{i 0} \mathbf{x}_{i t}=\mathbf{a}_{i}+\mathbf{A}_{i 1} \mathbf{x}_{i, t-1}+\mathbf{A}_{i 2} E_{t}\left(\mathbf{x}_{i, t+1}\right)+\mathbf{A}_{i 3} \mathbf{x}_{i t}^{*}+\mathbf{A}_{i 4} \mathbf{x}_{i, t-1}^{*}+\mathbf{A}_{i 5} E_{t}\left(\mathbf{x}_{i, t+1}^{*}\right)+\boldsymbol{\varepsilon}_{i t} \\
(2) \\
\mathbf{a}_{i}=\left(\begin{array}{c}
a_{i \pi} \\
a_{i y} \\
a_{i r}
\end{array}\right), \mathbf{A}_{i 0}=\left(\begin{array}{ccc}
1 & -\gamma_{i \pi} & 0 \\
0 & 1 & \gamma_{i y} \\
-\rho_{i \pi} & -\rho_{i y} & 1
\end{array}\right), \\
\mathbf{A}_{i 1}=\left(\begin{array}{ccc}
\lambda_{i \pi} & 0 & 0 \\
0 & \lambda_{i y} & 0 \\
0 & 0 & \rho_{i r}
\end{array}\right), \mathbf{A}_{i 2}=\left(\begin{array}{ccc}
1-\lambda_{i \pi} & 0 & 0 \\
\gamma_{i y} & 1-\lambda_{i y} & 0 \\
0 & 0 & 0
\end{array}\right)
\end{aligned}
$$




$$
\mathbf{A}_{i 3}=\left(\begin{array}{cc}
-\gamma_{i \pi} & 0 \\
1 & 0 \\
-\rho_{i y} & 0
\end{array}\right), \mathbf{A}_{i 4}=\left(\begin{array}{cc}
0 & 0 \\
-\lambda_{i y} & 0 \\
0 & 0
\end{array}\right), \mathbf{A}_{i 5}=\left(\begin{array}{cc}
0 & 0 \\
-\left(1-\lambda_{i y}\right) & 0 \\
0 & \lambda_{i r}
\end{array}\right)
$$

\subsection{The Solution}

One does not need to provide a model for $\mathbf{x}_{i t}^{*}$ for the purpose of estimation, given that they are weakly exogenous for the parameters of interest. However, one does need to provide a model for the purpose of forecasting, impulse response analysis or model solution. To obtain a solution to the above multivariate rational expectations model a statistical model for $\left(\mathbf{x}_{i t}^{*}, \varepsilon_{i t}\right)$ is also required.

In the DSGE literature the foreign variables, $\mathbf{x}_{i t}^{*}$, are typically assumed to be strictly exogenous, excluding any feedback from the lagged $\mathbf{x}_{i t}$. For a recent example see Adolfson, Laseén, Lindé and Villani (2005) where they combine a log-linearized DSGE model of Sweden written as (2) together with a VAR in $\mathbf{x}_{i t}^{*}$ given by

$$
\mathbf{x}_{i t}^{*}=\mathbf{a}_{i}^{*}+\mathbf{A}_{i}^{*} \mathbf{x}_{i, t-1}^{*}+\varepsilon_{i t}^{*},
$$

where it is assumed that $\varepsilon_{i t}$ and $\varepsilon_{i t}^{*}$ are independently distributed and are serially uncorrelated with zero means finite variances. This specification of the marginal model amounts to assuming that $\mathbf{x}_{i t}$ does not Granger cause $\mathbf{x}_{i t}^{*}$, which could be rather restrictive, considering that in a global context $\mathbf{x}_{i t}$ and $\mathbf{x}_{i t}^{*}$ are jointly determined. In practice, as noted in DdPS, it would be more realistic to assume that $\mathbf{x}_{i t}^{*}$ causes $\mathbf{x}_{i t}$ but only in the long run; thus allowing for possible short-run feedbacks from $\mathbf{x}_{i t}$ into $\mathbf{x}_{i t}^{*}$, (see Granger and Lin (1995), and Pesaran, Shin and Smith (2000)). There is the further problem that (3) is unlikely to be structurally stable, since it is specified in an ad hoc manner merely to complete the system. In the presence of breaks in the $\mathbf{x}_{i t}^{*}$ process the computation of the RE solution becomes even more demanding as likely futures changes in the process also need to be modelled. ${ }^{1}$

Assuming that the specified process for $\mathbf{x}_{i t}^{*}$ is stable and (approximately correct) the rational expectations solution of the DSGE model can be obtained by considering $\mathbf{x}_{i t}$ and $\mathbf{x}_{i t}^{*}$ jointly. For this purpose we first note that the economic model for $\mathbf{z}_{i t}=\left(\mathbf{x}_{i t}^{\prime}, \mathbf{x}_{i t}^{* \prime}\right)^{\prime}$ is now given by combining (2) and (3)

$$
\mathbf{A}_{i z 0} \mathbf{z}_{i t}=\mathbf{a}_{i z}+\mathbf{A}_{i z 1} \mathbf{z}_{i, t-1}+\mathbf{A}_{i z 2} E_{t}\left(\mathbf{z}_{i, t+1}\right)+\boldsymbol{\varepsilon}_{i z t}
$$

where

$$
\begin{aligned}
\mathbf{a}_{i z} & =\left(\begin{array}{c}
\mathbf{a}_{i} \\
\mathbf{a}_{i}^{*}
\end{array}\right), \boldsymbol{\varepsilon}_{i z t}=\left(\begin{array}{c}
\varepsilon_{i t} \\
\varepsilon_{i t}^{*}
\end{array}\right), \mathbf{A}_{i z 0}=\left(\begin{array}{cc}
\mathbf{A}_{i 0} & -\mathbf{A}_{i 3} \\
\mathbf{0} & \mathbf{I}_{k_{i}^{*}}^{*}
\end{array}\right), \\
\mathbf{A}_{i z 1} & =\left(\begin{array}{cc}
\mathbf{A}_{i 1} & \mathbf{A}_{i 4} \\
\mathbf{0} & \mathbf{A}_{i}^{*}
\end{array}\right), \mathbf{A}_{i z 2}=\left(\begin{array}{cc}
\mathbf{A}_{i 2} & \mathbf{A}_{i 5} \\
0 & 0
\end{array}\right),
\end{aligned}
$$

where $k_{i}^{*}$ is the dimension of $\mathbf{x}_{i t}^{*}$. Consider the quadratic matrix equation in $\mathbf{B}_{i z}$

$$
\mathbf{A}_{i z 2} \mathbf{B}_{i z}^{2}-\mathbf{A}_{i z 0} \mathbf{B}_{i z}+\mathbf{A}_{i z 1}=\mathbf{0}
$$

\footnotetext{
${ }^{1}$ The problem of forecasting time series subject to multiple structural breaks over long horizons is discussed in Pesaran, Pettenuzzo and Timmerman (2005).
} 
and suppose that there exists a real matrix solution to the above equation such that all the eigenvalues of $\mathbf{B}_{i z}$ and $\left(\mathbf{I}_{k_{i}+k_{i}^{*}}-\mathbf{A}_{i z 2} \mathbf{B}_{i z}\right)^{-1} \mathbf{A}_{i z 2}$ all lie inside or on the unit circle. Then the multivariate rational expectations model has a unique stable solution given by $^{2}$

$$
\mathbf{z}_{i t}=\mathbf{b}_{i z}+\mathbf{B}_{i z} \mathbf{z}_{i, t-1}+\mathbf{v}_{i t}
$$

where

$$
\left(\mathbf{A}_{i z 0}-\mathbf{A}_{i z 2} \mathbf{B}_{i z}-\mathbf{A}_{i z 2}\right) \mathbf{b}_{i z}=\mathbf{a}_{i z}
$$

and

$$
\left(\mathbf{A}_{i z 0}-\mathbf{A}_{i z 2} \mathbf{B}_{i z}\right) \mathbf{v}_{i t}=\varepsilon_{i z t} .
$$

Using the above solution and conditioning on $\mathbf{x}_{i t}^{*}$ yields the following $\operatorname{VARX}^{*}(1,1)$ structure:

$$
\mathbf{x}_{i t}=\mathbf{b}_{i}+\mathbf{B}_{1 i} \mathbf{x}_{i, t-1}+\mathbf{B}_{0 i}^{*} \mathbf{x}_{i t}^{*}+\mathbf{B}_{1 i}^{*} \mathbf{x}_{i, t-1}^{*}+\mathbf{u}_{i t},
$$

where $\mathbf{x}_{i t}^{*}$ and $\mathbf{u}_{i t}$ are uncorrelated and the reduced form parameters, $\mathbf{B}_{1 i}, \mathbf{B}_{0 i}^{*}$, and $\mathbf{B}_{1 i}^{*}$ can be estimated consistently by least squares. The structural rational expectations restrictions can be tested and imposed (if regarded as desirable) by noting the dependence of the reduced form parameters of the conditional model on the structural parameters of the DSGE model and the parameters assumed for the $\mathbf{x}_{i t}^{*}$ process.

The above rational expectations solution may be a reasonable approximation for certain purposes, but need not be consistent across $i$. This is because different marginal models of $\mathbf{x}_{i t}^{*}$ are assumed for each $i$ and there is nothing to ensure that they are consistent across $i$. An alternative approach, which is not subject to such shortcomings, would be to consider a global rational expectations solution. Suppose that the foreign variables are defined as fixed weighted averages of the associated variables, discussed further below, so that

$$
\mathbf{x}_{i t}^{*}=\sum_{j=0}^{N} w_{i j} \mathbf{x}_{j t}, w_{i i}=0, \sum_{j=0}^{N} w_{i j}=1 .
$$

For such fixed weights we have ${ }^{3}$

$$
\mathbf{z}_{i t}=\mathbf{W}_{i} \mathbf{x}_{t}
$$

where $\mathbf{x}_{t}=\left(\mathbf{x}_{0 t}^{\prime}, \mathbf{x}_{1 t}^{\prime}, \ldots, \mathbf{x}_{N t}^{\prime}\right)^{\prime}$, and the country-specific DSGE models (4) can be written as

$$
\mathbf{A}_{i z 0} \mathbf{W}_{i} \mathbf{x}_{t}=\mathbf{a}_{i z}+\mathbf{A}_{i z 1} \mathbf{W}_{i} \mathbf{x}_{t-1}+\mathbf{A}_{i z 2} \mathbf{W}_{i} E_{t}\left(\mathbf{x}_{t+1}\right)+\boldsymbol{\varepsilon}_{i t},
$$

for $i=0,1, \ldots, N$. Stacking these models now yields

$$
\mathbf{A}_{0} \mathbf{x}_{t}=\mathbf{a}_{x}+\mathbf{A}_{1} \mathbf{x}_{t-1}+\mathbf{A}_{2} E_{t}\left(\mathbf{x}_{t+1}\right)+\varepsilon_{t},
$$

\footnotetext{
${ }^{2}$ See, for example, Binder and Pesaran $(1995,1997)$.

${ }^{3}$ If the weights were time-varying we would need to provide a model for the future evolution of the weights as well.
} 
where

$$
\mathbf{A}_{j}=\left(\begin{array}{c}
\mathbf{A}_{0 z j} \mathbf{W}_{0} \\
\mathbf{A}_{1 z j} \mathbf{W}_{1} \\
\vdots \\
\mathbf{A}_{N z j} \mathbf{W}_{N}
\end{array}\right), \mathbf{a}_{x}=\left(\begin{array}{c}
\mathbf{a}_{0 z} \\
\mathbf{a}_{1 z} \\
\vdots \\
\mathbf{a}_{N z}
\end{array}\right), \boldsymbol{\varepsilon}_{t}=\left(\begin{array}{c}
\varepsilon_{0 t} \\
\varepsilon_{1 t} \\
\vdots \\
\boldsymbol{\varepsilon}_{N t}
\end{array}\right)
$$

As before, the rational expectations solution of the global structural model, assuming that it exists and is unique, is given by

$$
\mathbf{x}_{t}=\mathbf{b}+\mathbf{B} \mathbf{x}_{t-1}+\mathbf{v}_{t},
$$

where $\mathbf{B}$ satisfies the equations

$$
\mathbf{A}_{2} \mathbf{B}^{2}-\mathbf{A}_{0} \mathbf{B}+\mathbf{A}_{1}=\mathbf{0},
$$

with all its roots on or inside the unit circle and

$$
\left(\mathbf{A}_{0}-\mathbf{A}_{2} \mathbf{B}\right) \mathbf{v}_{t}=\varepsilon_{t} .
$$

Thus we see that the VARX* provides a general specification for macroeconomic models of small open economies, which can be stacked into a global model. This result is quite general and extends to other generalizations of the Keynesian open economy models discussed by Gali and Monacelli and others.

\subsection{Long-run relations}

The theory provides a variety of long-run relationships. If the variables are I(1) these will correspond to cointegrating relations, but there will also be stochastic trends. Such stochastic trends make long-run forecasts of variables very uncertain. But long-run relations are much more precisely estimated and most of the theory available, e.g. arbitrage conditions relate to long-run relationships. To capture these relationships one needs to have all the main variables for a country, just using panel data sets for a single variable (e.g. output, real exchange rate or equity prices) across many countries can abstract from important within and across country relationships. Country specific foreign variables are also needed because many long-run relations are international, e.g. purchasing power parity and the uncovered interest parity. The VARX* can handle both within and between country cointegration in a way that would be impossible in a system that did not impose any structure on the VAR model for the world economy.

In the case of the simple New Keynesian model the associated long run relations (which would be cointegrating if the variables were $\mathrm{I}(1)$ ) can be written as

$$
\begin{aligned}
y_{i t}-y_{i t}^{*} & =\mu_{1 i}+\xi_{1 i t} \\
r_{i t}-\pi_{i t} & =\mu_{2 i}+\xi_{2 i t} \\
\pi_{i t}-\theta_{i} \pi_{i t}^{*} & =\mu_{3 i}+\xi_{3 i t}
\end{aligned}
$$


where

$$
\mu_{1 i}=-a_{i \pi} / \gamma_{i \pi}, \mu_{2 i}=a_{i y} / \gamma_{i y},
$$

and assuming that $1-\rho_{i r}-\rho_{i \pi} \neq 0$,

$$
\theta_{i}=\lambda_{i r}\left(1-\rho_{i r}-\rho_{i \pi}\right)^{-1},
$$

and

$$
\mu_{3 i}=\left(1-\rho_{i r}-\rho_{i \pi}\right)^{-1}\left[a_{i r}+\rho_{i y} \mu_{1 i}-\mu_{2 i}\left(1-\rho_{i r}\right)\right] .
$$

The relation between domestic and foreign inflation depends on the monetary policy parameters at home and abroad and is one-to-one if

$$
\rho_{i r}+\rho_{i \pi}+\lambda_{i r}=1 .
$$

The Gali and Monacelli (2005) model also has a number of other relationships which could be included in any empirical implementation as long run relationships. Under certain assumptions, purchasing power parity holds in their model giving another long run relationship:

$$
e_{i t}+p_{t}^{*}-p_{i t}=\mu_{i P P P}+\xi_{i, P P P, t}
$$

where $e_{i t}$ is the log of the nominal exchange rate, $p_{t}^{*}$ is the log world price index and $p_{i t}$ is the log domestic price index. They also have

$$
y_{i t}-y_{i t}^{*}=\phi\left(e_{i t}+p_{i t}^{*}-p_{i t}\right) .
$$

If there were two cointegrating relations with both $y_{i t}-y_{i t}^{*}$ and $\left(e_{i t}+p_{t}^{*}-p_{i t}\right)$ $\mathrm{I}(0)$, this relationship would be consistent with a stationary output gap and real exchange rate. Alternatively the output gap and real exchange rate could be I(1) and cointegrate. Gali and Monacelli (2005) also have uncovered interest parity

$$
E_{t}\left(\Delta e_{i, t+1}\right)-\left(r_{i t}-r_{i t}^{*}\right)=\mu_{i, U I P}+\xi_{i, U I P, t}
$$

where $r_{i t}^{*}$ is the foreign interest rate, which again might be country specific, and one could test the restriction $\mu_{i U I P}=0$.

These are very similar to the long run relations used in GLPS, for the UK, which are:

$$
\begin{aligned}
& P P P: \boldsymbol{\xi}_{1 t}=\mu_{1}+p_{t}-p_{t}^{*}-e_{t} \\
& I R P: \xi_{2 t}=\mu_{2}+r_{t}-r_{t}^{*} \\
& C O N: \xi_{3 t}=\mu_{3}+y_{t}-y_{t}^{*} \\
& M D: \xi_{4 t}=\mu_{4}+\beta_{41} r_{t}+\beta_{42} t-\left(h_{t}-y_{t}\right) \\
& F R: \xi_{5 t}=\mu_{5}+r_{t}-\Delta \widetilde{p}_{t}
\end{aligned}
$$

The first, PPP, is the purchasing power parity relation between the logarithms of UK prices, foreign prices and the exchange rate. The second, IRP, is interest rate parity between UK and the foreign interest rate. The third, CON, is a convergence relation between the logarithms of UK and foreign GDP. The 
fourth, $\mathrm{MD}$, is a money demand equation, giving the logarithm of the highpowered money to income ratio as a function of interest rate and trend, with the latter capturing the technological advances that have taken place in the use of credit cards and other forms of payments. The fifth, FR, is the Fisher equation between UK interest rates and inflation. The oil price is included as an exogenous variable, but does not appear in any of the long-run relations. When applied to UK quarterly data in a cointegrating VAR by GLPS, the twenty three over-identifying restrictions implied by this structure are not rejected. Apart from the constants, there are only two freely estimated parameters, the coefficients of the interest rate and trend in the money demand function. Notice that three of the five have an international dimension. The evidence for PPP is stronger in this larger system than in typical tests which merely use data on $p_{t}, p_{t}^{*}$, and $e_{t}$. These disequilibrium terms have very significant effects on the system.

One would expect global effects to arise not only through the foreign variables, such as $y_{t}^{*}$,or $\pi_{t}^{*}$, but there will also be spillovers through the errors. Factors influencing the shocks to costs, $\varepsilon_{i, \pi t}$, to preferences or technology, $\varepsilon_{i, y t}$, and to policy, $\varepsilon_{i, r t}$, in different countries are likely to be similar. These covariances between the errors in different countries do not have implications for the rational expectations solution itself, but they would have implications for the variances. We discuss one interpretation of the sources of such covariations, common global factors, below.

The usual practice in DSGE modelling, is to use deviations from some ad hoc trend estimate e.g. the Hodrick-Prescott filter, which has no theoretical basis. A mispecified trend will bias estimates of short run dynamic relationships, and this procedure throws away information about long-run relationships between variables and does not allow testing of the theoretical restrictions, such as testing for common stochastic trends in certain variables. For example, in Gali and Monacelli (2005) whether there is a unit root in productivity influences the form of a number of their theoretical relationships. But in estimating the autoregressions for their exogenous processes, productivity and world, output they de-trend the time series using the HP filter first, which is likely to remove any unit root. This point is recognised in Del Negro et al. (2005), who note, 'We need to build models that can be successfully taken to non-detrended data models that fulfill Kydland and Prescott (1982)'s original promise of integrating growth and business cycle theory, so that they can at the same time match both growth and business cycle features of the data.' Within the approach proposed here, the equilibrium values of the variables, reflecting the long-run theory, can be easily calculated as the detrended long-horizon forecasts, discussed below.

The issue of how to relate the theory from DSGE type models to the data is a widely recognised problem. One approach, adopted by some central banks, is to build hybrid models with two distinct components: a theoretical core DSGE model supplemented with non-core equations. The non-core equations are statistical models of the discrepancy between the paths from the core model and the historical data. They would typically include additional variables and extra dynamics, subject to the restriction that the projected path for a variable 
should converge to the long-run equilibrium given by the theoretical core. This suggests that they believe that the theory can only be relied on in the long run, but the long run theory is not tested.

Another approach is taken in Del Negro et al. (2005). They have a closed economy New Keynesian DSGE model and approximate it by a VECM in first differences including some of the cointegrating relations. They find that including the cointegrating relations reduces the approximation error substantially. They also note that the high persistence of many of the exogenous processes (shocks) raises concerns about the ability of the DGSE to generate endogenous propagation mechanisms. This would be consistent with the theory providing more information about long-run relations than short-run reactions. Using Bayesian procedures they systematically relax the cross-equation restrictions implied by the DSGE, using a single parameter $\lambda$. They find that imposing the restrictions improves forecasting performance, which shows the value of using theory. However, the restrictions are not fully accepted, so a value of $\lambda$ that gives some weight to the restrictions but does not completely impose them seems best. Having a single parameter that measures the relative weight given to theory and data treats all the restrictions symmetrically. But as their results show, some of the restrictions seem to hold and others are strongly rejected by the data. One needs a more selective procedure in which one can look at the restrictions individually, imposing those which adequately represent the data and not imposing those that are rejected by the data. The approach set out in this paper provides one way of doing this.

\section{Econometrics Issues in the Analysis of the VARX*}

Suppose there are a set of countries $i=0,1,2, \ldots, N$, with country 0 , say the US, as the numeraire country. The objective is to model a particular country, say $i$. As an example a second-order country-specific $\operatorname{VARX}^{*}(2,2)$ model with deterministic trends can be written as

$$
\mathbf{x}_{i t}=\mathbf{B}_{i d} \mathbf{d}_{t}+\mathbf{B}_{i 1} \mathbf{x}_{i, t-1}+\mathbf{B}_{i 2} \mathbf{x}_{i, t-2}+\mathbf{B}_{i 0}^{*} \mathbf{x}_{i t}^{*}+\mathbf{B}_{i 1}^{*} \mathbf{x}_{i, t-1}^{*}+\mathbf{B}_{i 2}^{*} \mathbf{x}_{i, t-2}^{*}+\mathbf{u}_{i t},
$$

where $\mathbf{x}_{i t}$ is a $k_{i} \times 1$ (usually five or six) vector of domestic variables, $\mathbf{x}_{i t}^{*}$, a $k_{i}^{*} \times 1$ vector of foreign variables specific to country $i$, and $\mathbf{d}_{t}$ a $s \times 1$ vector of deterministic elements as well as observed common variables such as oil prices, typically $\left(1, t, p_{t}^{o}\right)^{\prime}$, but could contain seasonal or break dummy variables. The unknown coefficients are the $k_{i} \times s$ matrix $\mathbf{B}_{i d}$, the $k_{i} \times k_{i}$ matrices $\mathbf{B}_{i 1}$ and $\mathbf{B}_{i 2}$ of the lagged coefficients of domestic variables, $\mathbf{B}_{i 0}^{*}, \mathbf{B}_{i 1}^{*}$ and $\mathbf{B}_{i 2}^{*}$ are $k_{i} \times k_{i}^{*}$ matrix of coefficients of foreign variables specific to country $i$, and $\mathbf{u}_{i t}$ is a $k_{i} \times 1$ vector of idiosyncratic country-specific shocks, with $E\left(\mathbf{u}_{i t} \mathbf{u}_{j t}^{\prime}\right)=\boldsymbol{\Sigma}_{i j}=\boldsymbol{\Sigma}_{j i}^{\prime}$ and $E\left(\mathbf{u}_{i t} \mathbf{u}_{j t^{\prime}}^{\prime}\right)=\mathbf{0}$, for all $i, j$, and $t \neq t^{\prime}$.

The cointegrating VARX* ${ }^{*}$ can be written as a VECM

$$
\Delta \mathbf{x}_{i t}=\mathbf{B}_{i d} \mathbf{d}_{t}-\boldsymbol{\Pi}_{i} \mathbf{z}_{i, t-1}+\mathbf{B}_{i 0}^{*} \Delta \mathbf{x}_{i t}^{*}+\boldsymbol{\Gamma}_{i} \Delta \mathbf{z}_{i, t-1}+\mathbf{u}_{i t},
$$


where $\mathbf{z}_{i t}=\left(\mathbf{x}_{i t}^{\prime}, \mathbf{x}_{i t}^{* \prime}\right)^{\prime}$ and

$$
\begin{aligned}
\boldsymbol{\Pi}_{i} & =\left(\mathbf{I}-\mathbf{B}_{i 1}-\mathbf{B}_{i 2},-\mathbf{B}_{i 0}^{*}-\mathbf{B}_{i 1}^{*}-\mathbf{B}_{i 2}^{*}\right), \\
\boldsymbol{\Gamma}_{i} & =\left(-\mathbf{B}_{i 2},-\mathbf{B}_{i 2}^{*}\right) .
\end{aligned}
$$

As shown in Pesaran, Shin and Smith (2000), to ensure that the same deterministics prevail under different rank restrictions on $\boldsymbol{\Pi}_{i}$, the coefficients of the determinsitics components, $\mathbf{B}_{i d}$, need to be restricted so that they lie in the cointegrating space, namely we must have

$$
\mathbf{B}_{i d}=\boldsymbol{\Pi}_{i} \mathbf{\Upsilon}_{i}
$$

where $\boldsymbol{\Upsilon}_{i}$ is an unrestricted $\left(k_{i}+k_{i}^{*}\right) \times s$ matrix of constant coefficients. Under these restrictions and assuming that $\operatorname{rank}\left(\boldsymbol{\Pi}_{i}\right)=r_{i}<k_{i}+k_{i}^{*}$, we have $\boldsymbol{\Pi}_{i}=$ $\boldsymbol{\alpha}_{i} \boldsymbol{\beta}_{i}^{\prime}$, where $\boldsymbol{\beta}_{i}$ is the $\left(k_{i}+k_{i}^{*}\right) \times r_{i}$ matrix of the cointegrating coefficients and

$$
\Delta \mathbf{x}_{i t}=-\boldsymbol{\alpha}_{i} \boldsymbol{\beta}_{i}^{\prime}\left(\mathbf{z}_{i, t-1}-\mathbf{\Upsilon}_{i} \mathbf{d}_{t-1}\right)+\mathbf{B}_{i 0}^{*} \Delta \mathbf{x}_{i t}^{*}+\boldsymbol{\Gamma}_{i} \Delta \mathbf{z}_{i, t-1}+\boldsymbol{\Pi}_{i} \mathbf{\Upsilon}_{i} \Delta \mathbf{d}_{t}+\mathbf{u}_{i t}, \text { (6) }
$$

The $r_{i}$ error correction terms of the model can now be written as

$$
\boldsymbol{\xi}_{i t}=\boldsymbol{\beta}_{i}^{\prime} \mathbf{z}_{i t}-\boldsymbol{\beta}_{i}^{\prime} \mathbf{\Upsilon}_{i} \mathbf{d}_{t}=\boldsymbol{\beta}_{i x}^{\prime} \mathbf{x}_{i t}+\boldsymbol{\beta}_{i x *}^{\prime} \mathbf{x}_{i t}^{*}+\gamma_{i}^{\prime} \mathbf{d}_{t},
$$

The $\boldsymbol{\xi}_{i t}$ are mean zero $r_{i} \times 1$ vector of disequilibrium deviations from the long run relationships. In the case of small open economies it is reasonable to assume that the country specific foreign variables are "long run forcing" or $I(1)$ weakly exogenous, and then estimate the VARX* models separately for each country conditional on $\mathbf{x}_{i t}^{*}$, taking into account the possibility of cointegration both within $\mathbf{x}_{i t}$ and across $\mathbf{x}_{i t}$ and $\mathbf{x}_{i t}^{*}$. If there are $r_{i}$ cointegrating relations $r_{i}^{2}$ justidentifying long restrictions are required and any over-identifying restrictions can be tested.

Once the model is estimated, it is straightforward to estimate the trend components of the variables in the GVAR either using the multivariate BeveridgeNelson (BN) type decompositions, or adopt a recent suggestion by Garratt, Robertson and Wright (2005, GRW) and estimate the stochastic trend components of the model as the long horizon forecasts of the variables measured as deviations from their deterministic trends. The two approaches coincide in the absence of cointegration but could be different otherwise. ${ }^{4}$ Such decompositions allow the contribution of the various disequilibrium terms to the current values of the variables to be evaluated. Unlike the Hodrick-Prescott filter or other purely statistical approaches to trend/cycle decompositions the BN or GRW decompositions depend on the cointegrating properties of the GVAR and the long run theory that underlie them.

\section{The GVAR Model Illustrated}

All the 26 country-specific models in the GVAR of DdPS are estimated over the period 1979Q4-2003Q4 and the lag orders are selected by AIC separately

\footnotetext{
${ }^{4}$ See Chapter 10 in Garrett, Lee, Pesaran and Shin (2005) for further details and discussions.
} 
for each country up to a maximum of 2. Although this is a shorter lag than is common in many US VARs it allows for complex univariate dynamics. ${ }^{5}$ Different applications have different sets of variables, but in the DdPS version $\mathbf{x}_{i t}$ are a $k_{i} \times 1$ subset of the logarithm of real output, $y_{i t}$; inflation, $\pi_{i t}=p_{i t}-p_{i t-1}$, where $p_{i t}$ is the logarithm of a price index; the exchange rate variable, which is defined as $e_{i t}-p_{i t}$, where $e_{i t}$ is the logarithm of the nominal exchange rate against the dollar; a short interest rate, $r_{i t}^{S}=0.25 \log \left(1+R_{i t}^{S} / 100\right)$, where $R_{i t}^{S}$ is a short interest rate measured in percent per annum; a long interest rate, $r_{i t}^{L}=0.25 \log \left(1+R_{i t}^{L} / 100\right)$; and the logarithm of real equity prices, $q_{i t}$. The variables included in the different country models are not always the same, e.g. there are no equity price or long-term interest rate data for some. Money is included in the GLPS UK model and the PSW GVAR and the UK model also includes log relative domestic to foreign prices.

A coherent theoretical specification of the foreign variables $\mathbf{x}_{i t}^{*}$ is complicated and requires the development of multi-country models of trade and capital flows. In the empirical applications being reviewed here, the $\mathbf{x}_{i t}^{*}$ are calculated as country specific trade weighted averages of the corresponding variables of the other countries

$$
\mathbf{x}_{i t}^{*}=\sum_{j=0}^{N} w_{i j} \mathbf{x}_{j t}, \text { with } w_{i i}=0,
$$

where $w_{i j}$ is the share of country $j$ in the trade (exports plus imports) of country $i$. In some of the applications, the $\mathbf{x}_{i t}^{*}$ are treated as weakly exogenous, an assumption found acceptable, when tested. The VARX* models can be estimated separately for each country, taking into account the possibility of cointegration between $\mathbf{x}_{i t}$ and $\mathbf{x}_{i t}^{*}$. The foreign variables, $\mathbf{x}_{i t}^{*}$ would typically contain the same variables as the domestic, $\mathbf{x}_{i t}$, plus the exchange rate, thus there is a symmetrical structure to the model which can be given an economic interpretation.

As was emphasised above, for forecasting, impulse response analysis and solution of rational expectations models, we need to be able to predict the $\mathbf{x}_{i t}^{*}$ and examine how they would respond to shocks. In the UK model this is done by making them endogenous to the system (the oil price is treated as a random walk). In the GVAR they are solved for from the system as a whole.

It is straightforward to test the weak exogeneity assumption for the long-run parameters, of the country specific foreign variables because there are a small number of them. This simply involves running the regressions

$$
\Delta \mathbf{x}_{i t}^{*}=\mathbf{c}_{i 0}^{*}+\boldsymbol{\alpha}_{i}^{*} \boldsymbol{\xi}_{i, t-1}+\Gamma_{i}^{*} \Delta \mathbf{z}_{i, t-1}+\mathbf{u}_{i t}^{*},
$$

and testing that $\boldsymbol{\alpha}_{i}^{*}=0$.

\footnotetext{
${ }^{5}$ It is worth bearing in mind that the univariate representation of the variables in a VAR of order $p$ in $m$ variables is $A R M A(m p, m p-p)$. In DdPS's GVAR model where $p=2$ and $m=134$, the ARMA specification of the individual variables in the global model could be as high as $A R M A(268,266)$.
} 


\subsection{Solving the GVAR}

Although estimation is done on a country by country basis, the GVAR model is solved for the world as a whole, taking account of the fact that all the variables are endogenous to the system as a whole. To do this write (5) as

$$
\mathcal{A}_{i 0} \mathbf{z}_{i t}=\mathbf{h}_{i 0}+\mathbf{h}_{i 1} t+\mathcal{A}_{i 1} \mathbf{z}_{i t-1}+\mathcal{A}_{i 2} \mathbf{z}_{i t-2}+\mathbf{u}_{i t},
$$

for $i=0,1,2, \ldots, N$ where $\mathbf{z}_{i t}$

$$
\mathbf{z}_{i t}=\left(\begin{array}{c}
\mathbf{x}_{i t} \\
\mathbf{x}_{i t}^{*}
\end{array}\right)
$$

and

$$
\mathcal{A}_{i 0}=\left(\mathbf{I}_{k_{i}},-\mathbf{B}_{i 0}^{*}\right), \quad \mathcal{A}_{i 1}=\left(\mathbf{B}_{i 1}, \mathbf{B}_{i 1}^{*}\right), \quad \mathcal{A}_{i 2}=\left(\mathbf{B}_{i 2}, \mathbf{B}_{i 2}^{*}\right) .
$$

The dimensions of $\mathcal{A}_{i 0}, \mathcal{A}_{i 1}$ and $\mathcal{A}_{i 2}$ are $k_{i} \times\left(k_{i}+k_{i}^{*}\right)$ and $\mathcal{A}_{i 0}$ has full column rank, namely $\operatorname{Rank}\left(\mathcal{A}_{i 0}\right)=k_{i}$. Also note that

$$
\mathbf{z}_{i t}=\mathbf{W}_{i} \mathbf{x}_{t}
$$

where $\mathbf{x}_{t}=\left(\mathbf{x}_{0 t}^{\prime}, \mathbf{x}_{1 t}^{\prime}, \ldots, \mathbf{x}_{N t}^{\prime}\right)^{\prime}$ is the $k \times 1$ vector which collects all the endogenous variables of the system, and $\mathbf{W}_{i}$ is the $\left(k_{i}+k_{i}^{*}\right) \times k$ matrix defined by the trade weights $w_{i j}$. Using this (7) can be written as

$$
\mathcal{A}_{i 0} \mathbf{W}_{i} \mathbf{x}_{t}=\mathbf{h}_{i 0}+\mathbf{h}_{i 1} t+\mathcal{A}_{i 1} \mathbf{W}_{i} \mathbf{x}_{t-1}+\mathcal{A}_{i 2} \mathbf{W}_{i} \mathbf{x}_{t-2}+\mathbf{u}_{i t}, \text { for } i=0,1,2, \ldots, N,
$$

and the systems stacked to yield the model for $\mathbf{x}_{\mathbf{t}}$

$$
\mathbf{H}_{0} \mathbf{x}_{t}=\mathbf{h}_{0}+\mathbf{h}_{1} \mathbf{t}+\mathbf{H}_{1} \mathbf{x}_{t-1}+\mathbf{H}_{2} \mathbf{x}_{t-2}+\mathbf{u}_{t},
$$

where

$$
\mathbf{H}_{j}=\left(\begin{array}{c}
\mathcal{A}_{0 j} \mathbf{W}_{0} \\
\mathcal{A}_{1 j} \mathbf{W}_{1} \\
\vdots \\
\mathcal{A}_{N j} \mathbf{W}_{N}
\end{array}\right), \mathbf{h}_{j}=\left(\begin{array}{c}
\mathbf{h}_{0 j} \\
\mathbf{h}_{1 j} \\
\vdots \\
\mathbf{h}_{N j}
\end{array}\right), \mathbf{u}_{t}=\left(\begin{array}{c}
\mathbf{u}_{0 t} \\
\mathbf{u}_{1 t} \\
\vdots \\
\mathbf{u}_{N t}
\end{array}\right),
$$

for $j=0,1,2$. Since $\mathbf{H}_{0}$ is a known non-singular matrix that depends on the trade weights and parameter estimates, we can obtain the GVAR

$$
\mathbf{x}_{t}=\mathbf{a}_{0}+\mathbf{a}_{1} \mathbf{t}+\mathbf{G}_{1} \mathbf{x}_{t-1}+\mathbf{G}_{2} \mathbf{x}_{t-2}+\mathbf{v}_{t}
$$

where $\mathbf{G}_{j}=\mathbf{H}_{0}^{-1} \mathbf{H}_{j}, \mathbf{a}_{j}=\mathbf{H}_{0}^{-1} \mathbf{h}_{j}$, for $j=0,1,2$, and $\mathbf{v}_{t}=\mathbf{H}_{0}^{-1} \mathbf{u}_{t}$. The GVAR can be solved recursively and used for a variety of purposes.

There are no restrictions on the covariance matrix $\boldsymbol{\Sigma}=\mathbf{E}\left(\mathbf{v}_{t} \mathbf{v}_{t}^{\prime}\right)$. For each country we have a $k_{i} \times 1$ vector of estimated residuals $\widehat{\mathbf{u}}_{i t}$ from which can be calculated $\widehat{\mathbf{v}}_{i t}$ and the elements of the covariance matrix are estimated freely by the $k_{i} \times k_{j}$ matrix $\widehat{\boldsymbol{\Sigma}}_{i j}=\sum_{t} \widehat{\mathbf{v}}_{i t} \widehat{\mathbf{v}}_{j t}^{\prime} / T$.

Because it is based on consistently combining country specific open-economy models it contrasts with large global macroeconometric models, like Multimod. These are of the same structure as the large national macroeconometric models, which were displaced by VARs at a national level and subject to the same criticisms. 


\subsection{GVAR Estimates}

To illustrate some of the issues here we provide an overview of the GVAR model developed by DdPS. The model covers 33 countries, 8 grouped into a single euro area economy, using PPP GDP weights, giving 26 separate economies, as set out in Table 1.

Table 1: Countries and Regions in the GVAR Model

\begin{tabular}{lll}
\hline \hline United States & Euro Area & Latin America \\
China & Germany & Brazil \\
Japan & France & Mexico \\
United Kingdom & Italy & Argentina \\
& Spain & Chile \\
Other Developed Economies & Netherlands & Peru \\
Canada & Belgium & \\
Australia & Austria & \\
New Zealand & Finland & \\
& & \\
Rest of Asia & Rest of W.Europe & Rest of the World \\
Korea & Sweden & India \\
Indonesia & Switzerland & South Africa \\
Thailand & Norway & Turkey \\
Philippines & & Saudi Arabia \\
Malaysia & & \\
Singapore & & \\
\hline
\end{tabular}

The model is estimated over the period: 1979Q1-2003Q4. The US, the reference country, is treated differently from the other countries. Oil prices are included in the US model as an endogenous variable but included in other country models as weakly exogenous. Exchange rates (in terms of US dollars) are included as endogenous variables in all country models except for the US model. Also all foreign variables are included in the non-US models as weakly exogenous variables, but only foreign real output and foreign inflation are included as weakly exogenous in the US model.

The model has 134 endogenous variables 71 stochastic trends and 63 cointegrating relations. All the roots of the GVAR either lie on or inside the unit circle. The long run forcing assumption is rejected only in 5 out of 153 cases. DdPS report the results for various tests of structural stability, the critical values of which are computed using the sieve bootstrap samples obtained from the solution of the GVAR. Evidence of structural instability is found primarily in the error variances (47\% of the equations - clustered in the period 1985-1992). Although linear with a simple overall structure, this is a large and complicated model which 
allows for a large degree of interdependence. There are three routes for between country interdependence: through the impact of the $\mathbf{x}_{i t}^{*}$ variables, oil prices, and through the error covariances. The effects through the $\mathbf{x}_{i t}^{*}$ are generally large, shocks to one country have marked effects on other countries. The between country error covariances are quite small, with the exception of those for the real exchange rate equations, perhaps because of the base-country effect, since they are all expressed against the US dollar.

Table 2: Domestic and Foreign Variables in All Models Excluding the

\begin{tabular}{ccc}
\multicolumn{3}{c}{ US } \\
\hline \hline Variable & Domestic & Foreign \\
\hline real output & $y_{i t}$ & $y_{i t}^{*}$ \\
inflation & $\pi_{i t}$ & $\pi_{i t}^{*}$ \\
real exchange rate & $\left(e_{i t}-p_{i t}\right)$ & - \\
real equity prices & $q_{i t}$ & $q_{i t}^{*}$ \\
short-term interest rate & $r_{i t}^{S}$ & $r_{i t}^{* S}$ \\
long-term interest rate & $r_{i t}^{L}$ & $r_{i t}^{* L}$ \\
oil prices & - & $p_{t}^{o}$ \\
\hline
\end{tabular}

\subsection{Generalised impulse Response Functions}

The GVAR provides a theoretically coherent framework for modelling the global interactions. The standard way of examining economic interactions, whether national or global, is through impulse response function analysis. This examines the effect of a typical shock, usually one standard error, on the time path of the variables of the model. These shocks can be to observables, e.g. the oil price or interest rate, or to unobservables, an oil price demand shock or a monetary policy shock. Shocks to observables can be calculated directly using Generalized Impulse Response Functions, GIRFs, discussed in GLPS. These require no identifying assumptions and use the estimated error covariances to allow for the contemporaneous linkages between shocks. The effect of the shock to the observable on the other variables is of considerable interest in itself and should certainly be the first stage of any analysis. It can be interpreted as the effect on the variables in the model of an intercept adjustment to the particular equation, e.g. the oil price or interest rate equation. However, for some purposes, we may wish to know where the shocks to observables come from. For the oil price, we may want to decompose the observable shock into the unobservable shock to demand, to supply and to their covariance; similarly for interest rates we may want to decompose the observable shock into the systematic part of monetary policy, 
the monetary policy shock and their covariance. In general, these covariances will be non-zero: a demand shock to oil which raises price, could change the behaviour of oil producers that target a given level foreign exchange revenues. However, to decompose the observable shock into its unobserved components requires more information, which is provided by the just identifying assumptions, e.g. a particular causal ordering of the variables in a Choleski decomposition. Since just identifying assumptions are not testable, it may be difficult to obtain agreement on the appropriate nature of such assumptions. Furthermore, even if one could agree on an appropriate ordering of the variables within a country, it is unlikely that one would be able to agree on an ordering between countries.

Thus the natural starting point in the analysis of interactions is the GIRFs. DdPS present boostrap means and 90\% confidence bounds for the impulse response functions to deal with parameter uncertainty. GIRFs are presented for the US and euro area (EA) in response to one standard error shock to US real equity prices, US short interest rates and oil prices. They also consider an identified shock to US monetary policy and the effect of a global shock. This empirical analysis suggests a number of features. Financial shocks (equity and bond prices) tend to be transmitted much faster than shocks to real output and/or inflation. Equity and bond markets seem to be far more synchronous as compared to the foreign exchange markets. Further research is needed for understanding the factors that lie behind exchange rate interdependencies. The effects of output shocks across countries is less synchronous than inflation shocks, which is still less synchronous than the effects of shocks to financial variables.

Here we consider another question: how different are the UK and EA, in their response to external shocks? This is done by calculating GIRFs and their $90 \%$ bootstrap bounds over 24 quarters for the responses of the UK and EA values of six variables (output, inflation, real equity prices, exchange rate and short and long interest rates) to various external shocks. The shocks we consider are one standard error negative shocks to US output and real equity prices and a one standard error positive shock to oil prices. The plots of the GIRFs are shown in Figures 1 to 3 . There are two questions we can ask about the GIRFs: what is the sign and size of the effect and what is the significance of the effect. In some cases the effect may be large, but because of the size of the standard errors, statistically insignificant; in other cases the effect may be small, but being very precisely estimated, highly significant.

A negative shock to US output reduces inflation, and short and long term interest rates in both the UK and EA. This is the response that would be expected. The interest rate effects are significant, depressing UK and EA short and long rates by similar magnitudes, with the size 
of the effect starting out close to zero, increasing and then stabilising. Effects on real exchange rates and equity prices are very small in both countries. The negative shock to US output has a positive effect on UK output and a negative effect on EA output, though neither are significant.

A negative shock to US real equity prices also has a significant negative effect on UK and EA interest rates of similar magnitudes in each and a negative effect on UK and EA output, which is significant only in the short run for the UK, but significant in both the short and long-run for the EA. If the negative US equity shock signalled a reduction in the expected rate of return one would expect lower interest rates and lower output in this way. There is a significant negative effect from the US equity shock on the EA real exchange rate, but it quickly becomes insignificant and significant short-run negative effects on UK and EA equity prices, which die away in the long-run. In response to the negative equity shock, inflation is reduced in both the UK and EA.

A one standard error increase in oil prices has a positive impact effect on EA inflation, which is significant and on short interest rates which is close to significance; but has very little effect on these variables in the UK, perhaps because it is an oil producer. It also has quite a large positive impact effect on EA and UK long interest rates, which are significant in the short run. The output and exchange rate effects are very small in both EA and UK.

The GIRFs indicate the importance of allowing for the international linkages: shocks to observables transmit internationally. In addition, both the fact that there are a lot of large significant responses by interest rates and the fact that the equity price shocks have significant impacts, indicates that it is particularly important to allow for international financial linkages. The GIRFs also indicate a great deal of similarities in the UK and EA responses, particularly in interest rate responses.

\section{$5 \quad$ Factor Models}

Recently, there has been a resurgence of interest in factor models for the analysis of international transmission mechanisms and for forecasting, and it would be of some interest to see how the GVAR relates to the factor models. To this end suppose the country specific variables, $\mathbf{x}_{i t}$, are determined, by some observed factors, $\mathbf{d}_{t}$, which could include deterministic elements, a number of unobserved common factors, $\mathbf{f}_{t}$, and a vector of idiosyncratic errors, $\boldsymbol{\varepsilon}_{i t}$, that are weakly dependent across $i$, namely

$$
\mathbf{x}_{i t}=\boldsymbol{\Lambda}_{d i} \mathbf{d}_{t}+\boldsymbol{\Lambda}_{f i} \mathbf{f}_{t}+\varepsilon_{i t}
$$


Aggregate using the common set of weights $w_{j}$, we obtain

$$
\sum_{j=0}^{N} w_{j} \mathbf{x}_{j t}=\left(\sum_{j=0}^{N} w_{j} \boldsymbol{\Lambda}_{d j}\right) \mathbf{d}_{t}+\left(\sum_{j=0}^{N} w_{j} \boldsymbol{\Lambda}_{f j}\right) \mathbf{f}_{t}+\sum_{j=0}^{N} w_{j} \varepsilon_{j t},
$$

or

$$
\mathbf{x}_{t}^{*}=\boldsymbol{\Lambda}_{d}^{*} \mathbf{d}_{t}+\boldsymbol{\Lambda}_{f}^{*} \mathbf{f}_{t}+\varepsilon_{t}^{*}
$$

Pesaran (2004) shows that under some weak assumptions as $N \rightarrow \infty$, the factors converge in quadratic mean to

$$
\mathbf{f}_{t} \stackrel{q . m .}{\rightarrow}\left(\boldsymbol{\Lambda}_{f}^{* \prime} \boldsymbol{\Lambda}_{f}^{*}\right)^{-1} \boldsymbol{\Lambda}_{f}^{*}\left(\mathbf{x}_{t}^{*}-\boldsymbol{\Lambda}_{d}^{*} \mathbf{d}_{t}-\varepsilon_{t}^{*}\right)
$$

The $\mathbf{x}_{t}^{*}$ and the observed factors proxy for the unobserved global factors, so including them in the equations of interest for the individual countries will reduce the common omitted variable bias. Including the $\mathbf{x}_{t}^{*}$, in the equations for individual countries, also reduces between country dependence in the errors induced by the omitted global factors.

The issue is how to choose the weights. They can be either specified a priori or estimated. In a panel context Pesaran (2004) suggests using $w_{j}=1 /(N+1)$, equal weights, so $\mathbf{x}_{t}^{*}=\overline{\mathbf{x}}_{t}$. In the context of nationalglobal modelling country specific trade weights are sensible, being the linear combination of other countries that are most important to the country concerned, so using the weights $w_{i j}$ the common factor estimates, $\mathbf{x}_{t}^{*}$, will be replaced by $\mathbf{x}_{i t}^{*}$.

An alternative approach would be to estimate the weights as factor loadings directly, e.g. by constructing the factors as principal components, extracted from the pooled set of all the variables in the world economy, or across a given geographical region. In many cases it is difficult to give these estimated factors an economic interpretation. This is a particular problem when there are many variables for many countries, since it may not be obvious how to identify the factors. The estimation may induce errors and principal component methods seem to perform worse than a priori weights in Monte Carlo studies in a panel context, e.g. Kapetanios and Pesaran (2005). There is also the problem that a factor which is crucial for one country or region may account for small part of global variance and get ignored, which country specific trade weights avoids.

Recent examples of the factor approach are the factor augmented VARs. FAVARs are used to measure US monetary policy in Bernanke Boivin and Eliasz (2005, BBE); UK monetary policy in Lagana and Mountford (2005, LM), and are discussed in more detail by Stock and Watson (2005, SW). Although FAVARs have not been applied in a global 
setting, in principal they could, thus it may be useful to compare VARX* and FAVAR structures.

Consider a $M \times 1$ vector of observed focus variables $\mathbf{Y}_{t}$, a $K \times 1$ vector of unobserved factors $\mathbf{F}_{t}$ with a VAR structure

$$
\left(\begin{array}{c}
\mathbf{F}_{t} \\
\mathbf{Y}_{t}
\end{array}\right)=\boldsymbol{\Phi}(L)\left(\begin{array}{c}
\mathbf{F}_{t-1} \\
\mathbf{Y}_{t-1}
\end{array}\right)+\mathbf{v}_{t}
$$

The unobserved factors are related to a $N \times 1$ vector $\mathbf{X}_{t}$, which contains a large number (BBE use $N=120, \mathrm{LM} N=105$ ) of potentially relevant observed variables by

$$
\mathbf{X}_{t}=\Lambda^{f} \mathbf{F}_{t}+\Lambda^{y} \mathbf{Y}_{t}+\mathbf{e}_{t}
$$

where the $\mathbf{F}_{t}$ are estimated as the principal components of the $\mathbf{X}_{t}$. It is common to use an arbitrary statistical assumption to identify the factors, but other assumptions are possible.

The argument is that (a) a small number of factors can account for a large proportion of the variance of the $\mathbf{X}_{t}$ and thus parsimoniously reduce omitted variable bias in the VAR (10); (b) the factor structure for $X_{t}$ in (11) allows one to calculate impulse response functions for all the elements of $\mathbf{X}_{t}$ in response to a (structural) shock in $\mathbf{Y}_{t}$; (c) the factors may be better measures of underlying theoretical variables such as economic activity than the observed proxies such as GDP or industrial production. In addition, FAVARs may forecast better than standard VARs. The factors play a similar role to $\mathbf{x}_{i t}^{*}$ in (10) and the structure of (11) is the same as that of satellite models driven by the VARX*, GLPS gives some examples of these.

In the current FAVARs, very little theory is used. In particular they do not use or test for long-run cointegrating or theoretical relations. If this were done, there would be an additional set of just identifying restrictions needed to match the $\mathbf{F}_{t}$ to the theoretical concepts that appear in the cointegrating relations. BBE motivate the exercise with the standard 3 equation model with the factors measuring the natural level of output and supply shocks, but do not use this interpretation in the empirical work, though they note the need to interpret the estimated factors more explicitly. Following the practice in earlier work by SW, it is standard to transform most of the $\mathbf{X}_{t}$ by first differencing. This results in loss of a great deal of long-run information, since ratios and spreads are not included in the information set. For example, FAVARs based on differences of interest rates do not take account of the information on the term structure, a problem SW note.

The dynamic factor structure leads to testable over-identifying restrictions, which SW find are rejected for BBE type models, but the economic 
effect of rejection is small. The standard errors produced by the two-step estimates of (10) are subject to the generated regressor problem and can lead to misleading inference. It is not clear how well the large sample results, when $\mathbf{F}_{t}$ can be treated as known, work in practice.

Choosing $M$ and $K$, the number of focus variables and the number of factors, raises difficult issues. SW for the US and LM for the UK argue for 7 factors, $\mathrm{BBE}$ argue for smaller numbers e.g. $M=3, K=1$, or $M=1, K=3$. If a large number of factors are needed, it reduces the attraction of the procedure and may make interpretation of the factors more difficult. The procedure is sensitive to the choice of $\mathbf{X}_{t}$. Just making the set of variables large does not solve the problem, because there may be factors that are very important in explaining $\mathbf{X}_{t}$, but do not help in explaining $\mathbf{Y}_{t}$, and vice versa.

LM largely follow BBE in selecting the set of variables $\mathbf{X}_{t}$, but the relevant variables are likely to be very different for a small open economy like the UK than a large almost closed economy like the US, a fact LM note. In particular, they do not consider any foreign variables apart from some trade variables. They note that UK monetary authorities would take account of US interest rates, but do not include them in $\mathbf{X}_{t}$. The estimated factors explain a much smaller proportion of the variance of the $\mathbf{X}_{t}$ in the UK than in the US application.

Using the constructed $\mathbf{x}_{i t}^{*}$ has the advantage that they have a natural theoretical interpretation and use the information in trade patterns. However, construction of an open economy FAVAR and comparison with a VARX* may be an interesting research question.

\section{Concluding Remarks}

The VARX* structure allows for global influences on core domestic variables; allows the core to drive satellite subsystems, such as for the labour market; and allows the VARX* models to be consistently combined to provide a Global VAR. The VARX* is of the same form as the solution to a DSGE model so can be given a theoretical interpretation and it allows over-identifying long-run theoretical relations to be tested as restrictions on cointegrating vectors and imposed if acceptable. This gives the system a transparent long-run theoretical structure. Similarly, short-run over-identifying theoretical restrictions, e.g. from rational expectations, can be tested and imposed if accepted. Alternatively, if one has less confidence in the short-run theory, the dynamics can be left unrestricted. The assumption of the weak exogeneity of the foreign variables, $\mathbf{x}_{i t}^{*}$, for the long-run parameters can be tested and the $\mathbf{x}_{i t}^{*}$ can be interpreted as proxies for global factors. Rather than using deviations from ad hoc 
statistical trends, the equilibrium values of the variables reflecting the long-run theory embodied in the model can be calculated. GVARs have been used for a wide variety of purposes. A substantive empirical conclusion is that shocks to financial variables, equity prices and interest rates, transmit internationally faster and more significantly than shocks to real variables. While it is crucial to allow for international linkages, it is particularly important to allow for international financial linkages, which many global models do not do. Further theoretical and empirical developments of the GVAR modelling include: a closer integration of the multi-country trade models and the GVAR framework; testing short run and long run restrictions; calculation of equilibrium values for the variables; a more detailed analysis of business cycle synchronization; multi-period point and probability forecasting and forecast evaluation, and further uses of the GVAR in credit risk analysis and for strategic asset management. 


\section{References}

Adolfson, M., S. Laseen, J. Linde and M. Villani (2005) Bayesian Estimation of an open economy DSGE model with incomplete pass-through, Sveriges Riksbank Working Paper Series, No. 179.

Bernanke, B.S. J. Boivin and P. Eliasz (2005) Measuring the Effects of Monetary Policy: A Factor-Augmented Vector Autoregressive (FAVAR) approach, Quarterly Journal of Economics, Feb 387-422.

Binder, M. and M.H. Pesaran (1995) Multivariate Rational Expectations Models and Macroeconomic Modelling: a review and some new results. In M.H. Pesaran and M. Wickens (eds) Handbook of Applied Econometrics, vol 1, 655-673.

Binder, M. and M.H. Pesaran (1997) "Multivariate linear rational expectations models: characterization of the nature of the solutions and their fully recursive computation", Econometric Theory, 13, 877-888

Breitung, J. and M.H. Pesaran (2005) Unit Roots and Cointegration in Panels, forthcoming in L. Matyas, and P. Sevestre, The Econometrics of Panel Data (Third Edition), Kluwer Academic Publishers.

Dees, S., F. di Mauro, M.H.Pesaran and L.V. Smith (2005) Exploring the International Linkages of the Euro Area: A Global VAR analysis, CESifo Working paper No1425.

Del Negro, M. F. Schorfeide, F. Smets and R. Wouters (2005) On the Fit and Forecasting Performance of New-keynesian Models, European Central Bank Working Paper No 491.

Gali, J. and T. Monacelli (2005) Monetary Policy and Exchange Rate Volatility in a Small Open Economy, Review of Economic Studies, 72, 707-734.

Garratt, A., K.Lee, M.H. Pesaran and Y. Shin (2003a) A Long Run Structural Model of the UK, Economic Journal, 113, 487, 412-455.

Garratt, A., K.Lee, M.H. Pesaran and Y. Shin (2003b) Forecast Uncertainty in Macroeconometric Modelling: an application to the UK economy, Journal of The American Statistical Association, 98, 464, 829-838.

Garratt, A., K.Lee, M.H. Pesaran and Y. Shin (2006) Global and National Macroeconometric Modelling: A long-run structural approach, Oxford University Press, forthcoming.

Garratt, A., D. Robertson and S. Wright (2005) Permanent versus Transitory Components and Economic Fundamentals, Journal of Applied Econometrics, forthcoming.

Granger C.W. and J-L Lin (1995) Causality in the Long Run, Econometric Theory 11, 530-536.

Kapetanios, G., and M.H. Pesaran (2005) Alternative Approaches to Estimation and Inference in Large Multifactor Panels: Small Sample 
Results with an Application to Modelling Asset Returns, forthcoming in Garry Phillips and Elias Tzavalis (eds) The Refinement of Econometric Estimation and Test Procedures: Finite Sample and Asymptotic Analysis, Cambridge University Press, Cambridge.

Kydland, F., and E. Prescott (1982) Time to Build and Aggregate Fluctuations, Econometrica, 50, 1345-70.

Lagana G. and A. Mountford (2005) Measuring Monetary Policy in the UK: A Factor-Augmented Vector Autoregression Model Approach, Manchester School, Supplement, 77-98.

Pesaran, M.H. (2004) Estimation and Inference in Large Heterogeneous Panels with a Multifactor Error Structure, CESifo Working Paper No. 1331.

Pesaran, M.H., D. Pettenuzzo and A Timmerman (2005) Forecasting Time Series Subject to Multiple Structural Breaks, Revised version of Cambridge Working Papers in Economics, No. 0433.

Pesaran M.H., T. Schuermann, and S.M. Weiner (2004) Modelling Regional Interdependencies using a Global Error Correcting Macroeconometric Model, Journal of Business and Economic Statistics, 22, 129-162.

Pesaran, M.H., T. Schuermann, B.J. Treutler and S.M. Weiner (2005) Macroeconomic Dynamics and Credit Risk: A Global Perspective, forthcoming, Journal of Money, Credit and Banking; available as Wharton Financial Institutions Center Working Paper \#03-13B.

Pesaran M.H., T. Schuermann, and B.J. Treutler (2005) Global Business Cycles and Credit Risk, NBER Working paper 11493, forthcoming in Mark Carey and Rene Stulz (eds) Risks of Financial Institutions, Chicago, IL, University of Chicago Press.

Pesaran, M.H., Y. Sin and R.J. Smith (2000) Structural Analysis of Vector Error Correction Models with Exogenous I(1) Variables, Journal of Econometrics, 97, 293-343.

Pesaran M.H., L.V. Smith and R.P. Smith (2005) What if the UK had Joined the Euro in 1999? An empirical evaluation using a Global VAR, CESifo Working Paper 1477.

Stock, J.H. and M. W. Watson (2005) Implications of Dynamic Factor Models for VAR Analysis, NBER Working Paper 11467. 
Figure 1a: Generalized Impulse Responses of a Negative Unit (-1б) Shock to U.S. Real Output on Macroeconomic Variables in the E.A. (Bootstrap Mean Estimates together with 90\% Bootstrap Bounds)

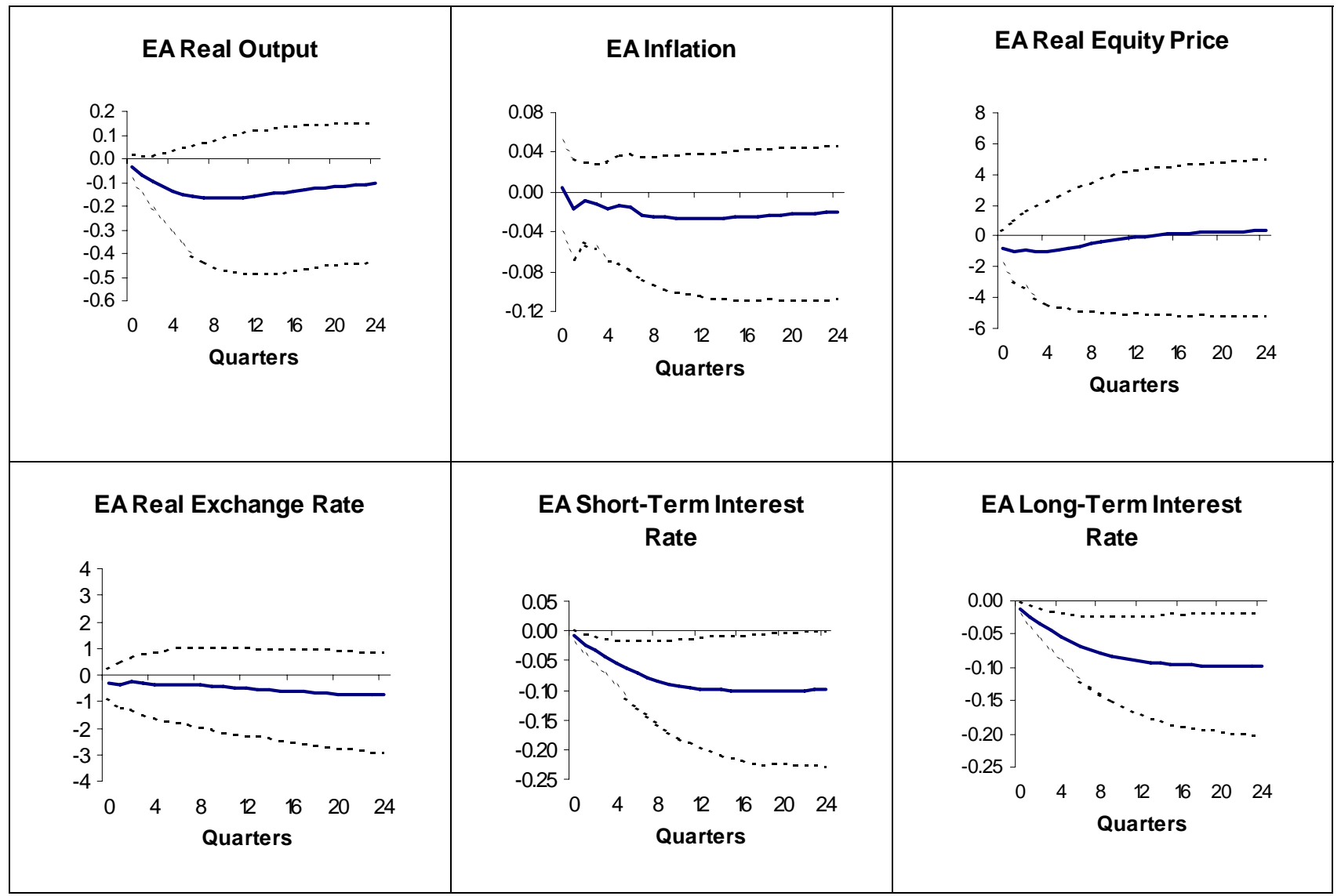

Figure 1b: Generalized Impulse Responses of a Negative Unit (-1б) Shock to U.S. Real Output on Macroeconomic Variables in the U.K. (Bootstrap Mean Estimates together with 90\% Bootstrap Bounds)

\begin{tabular}{|c|c|c|}
\hline 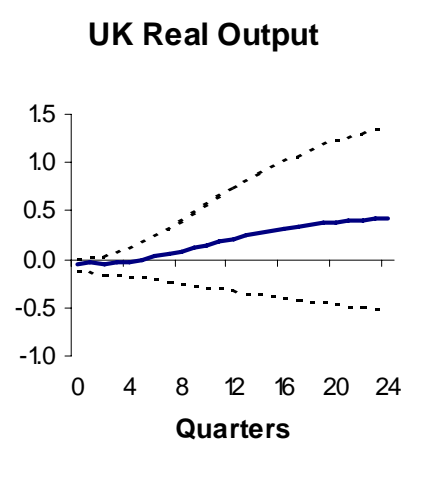 & 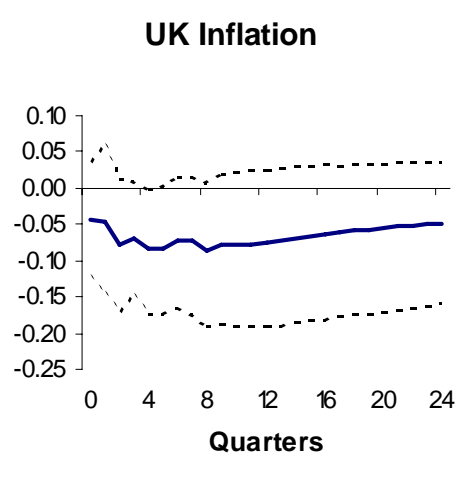 & 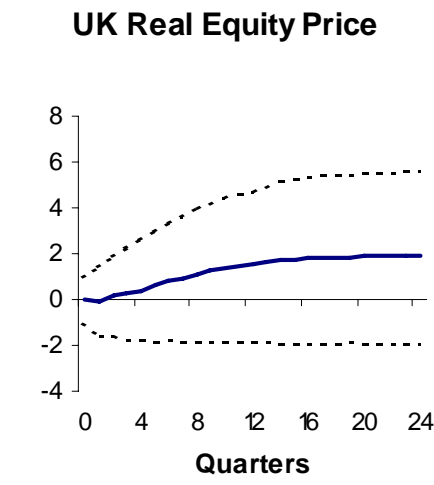 \\
\hline 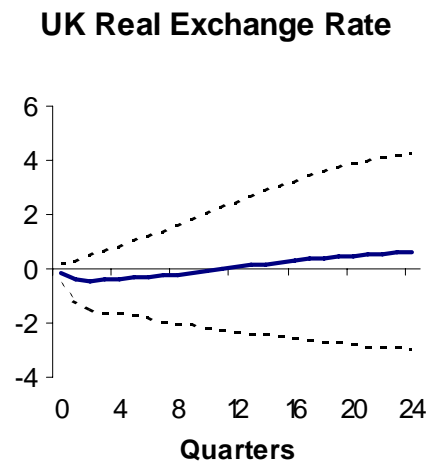 & 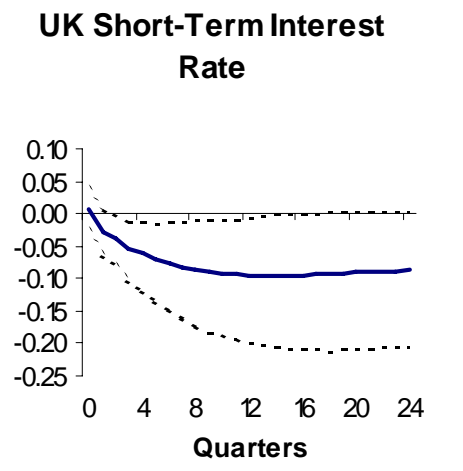 & 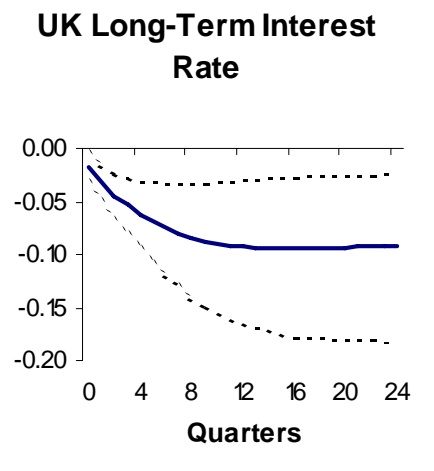 \\
\hline
\end{tabular}


Figure 2a: Generalized Impulse Responses of a Negative Unit (-1б) Shock to U.S. Real Equity Prices on Macroeconomic Variables in the E.A. (Bootstrap Mean Estimates together with 90\% Bootstrap Bounds)

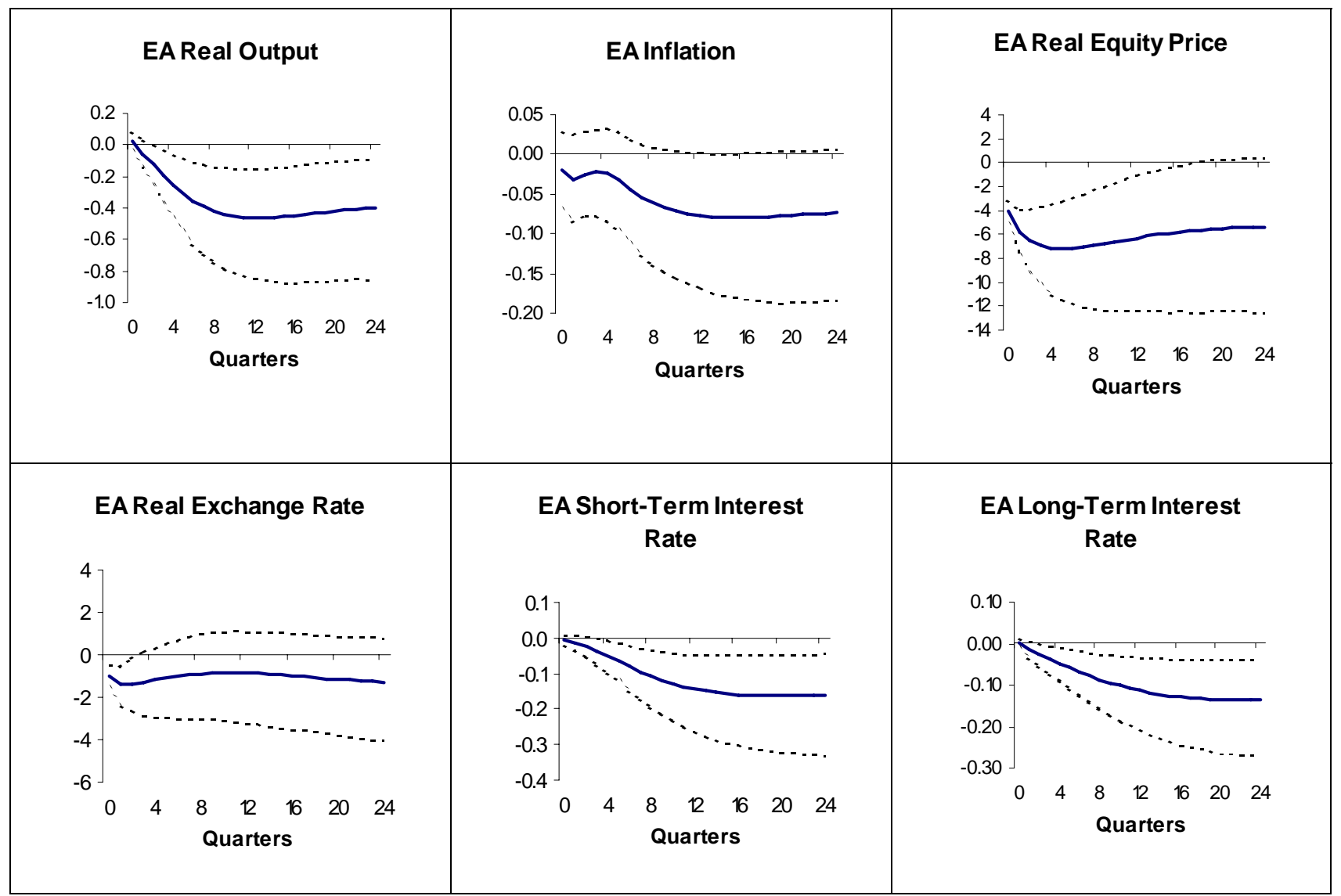

Figure 2b: Generalized Impulse Responses of a Negative Unit (-1б) Shock to U.S. Real Equity Prices on Macroeconomic Variables in the U.K. (Bootstrap Mean Estimates together with 90\% Bootstrap Bounds)

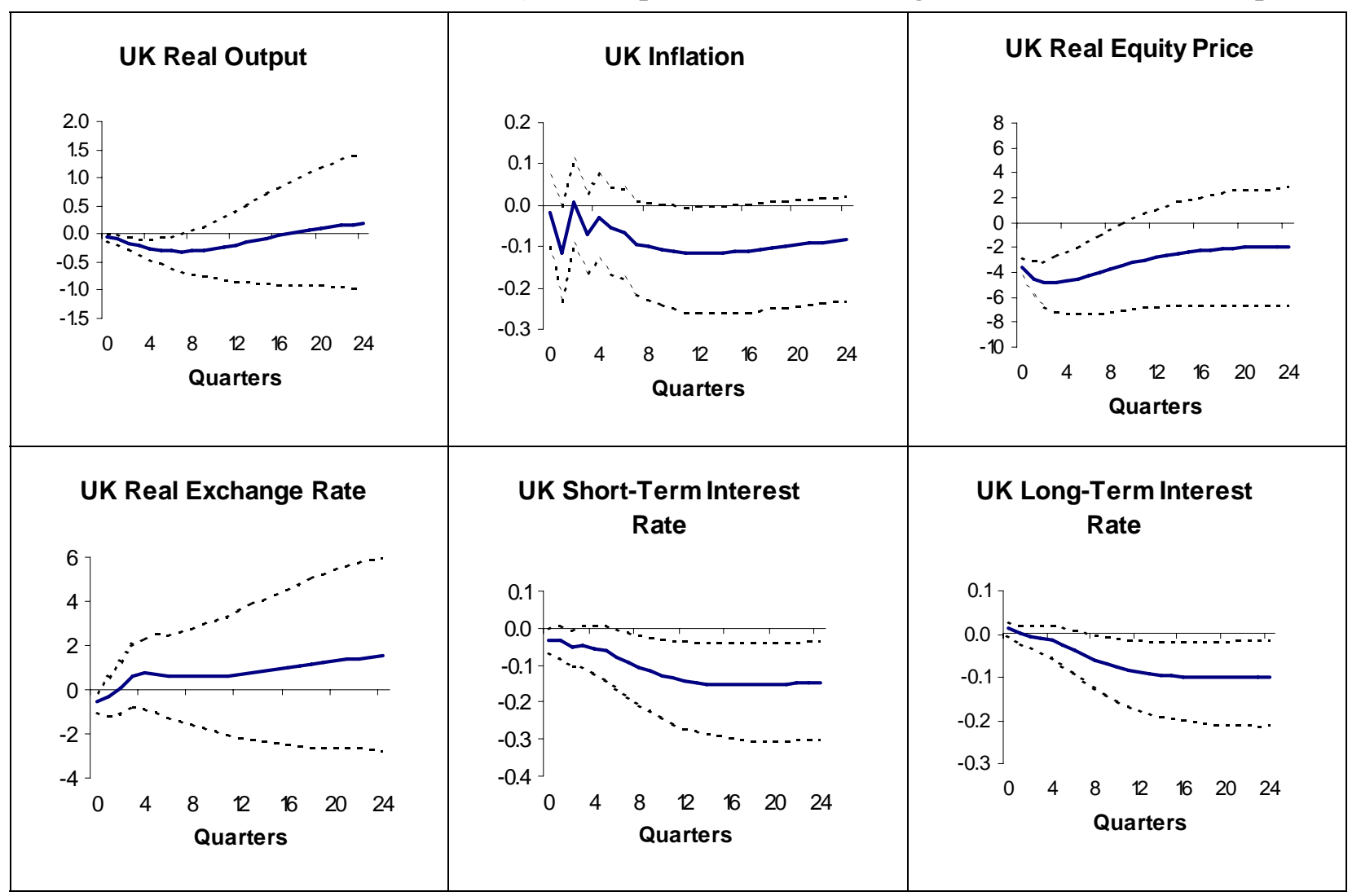


Figure 3a: Generalized Impulse Responses of a Positive Unit (+1 $)$ Shock to Oil Prices on Macroeconomic Variables in the E.A. (Bootstrap Mean Estimates together with 90\% Bootstrap Bounds)

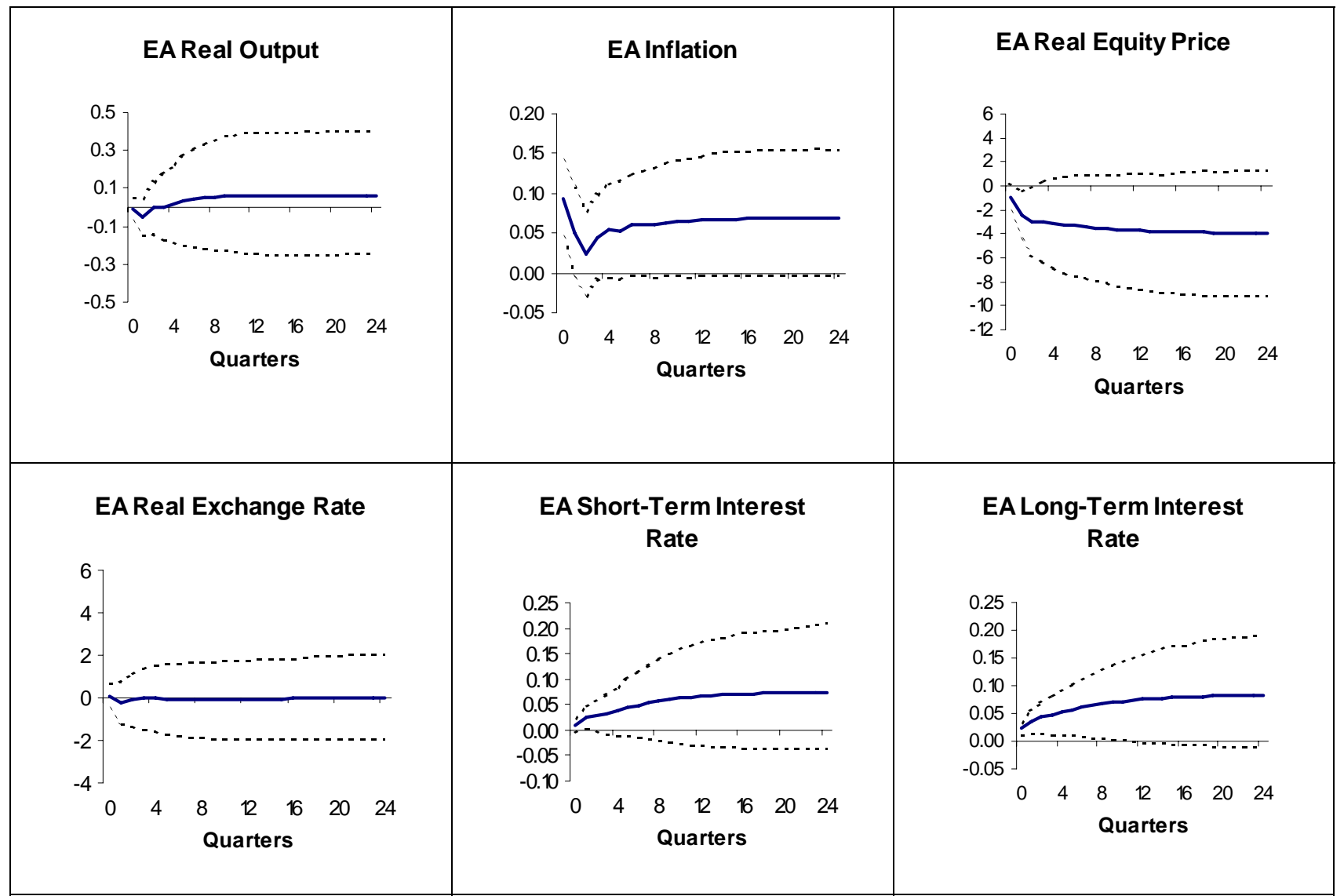

Figure 3b: Generalized Impulse Responses of a Positive Unit $(+1 \sigma)$ Shock to Oil Prices on Macroeconomic Variables in the U.K. (Bootstrap Mean Estimates together with 90\% Bootstrap Bounds)

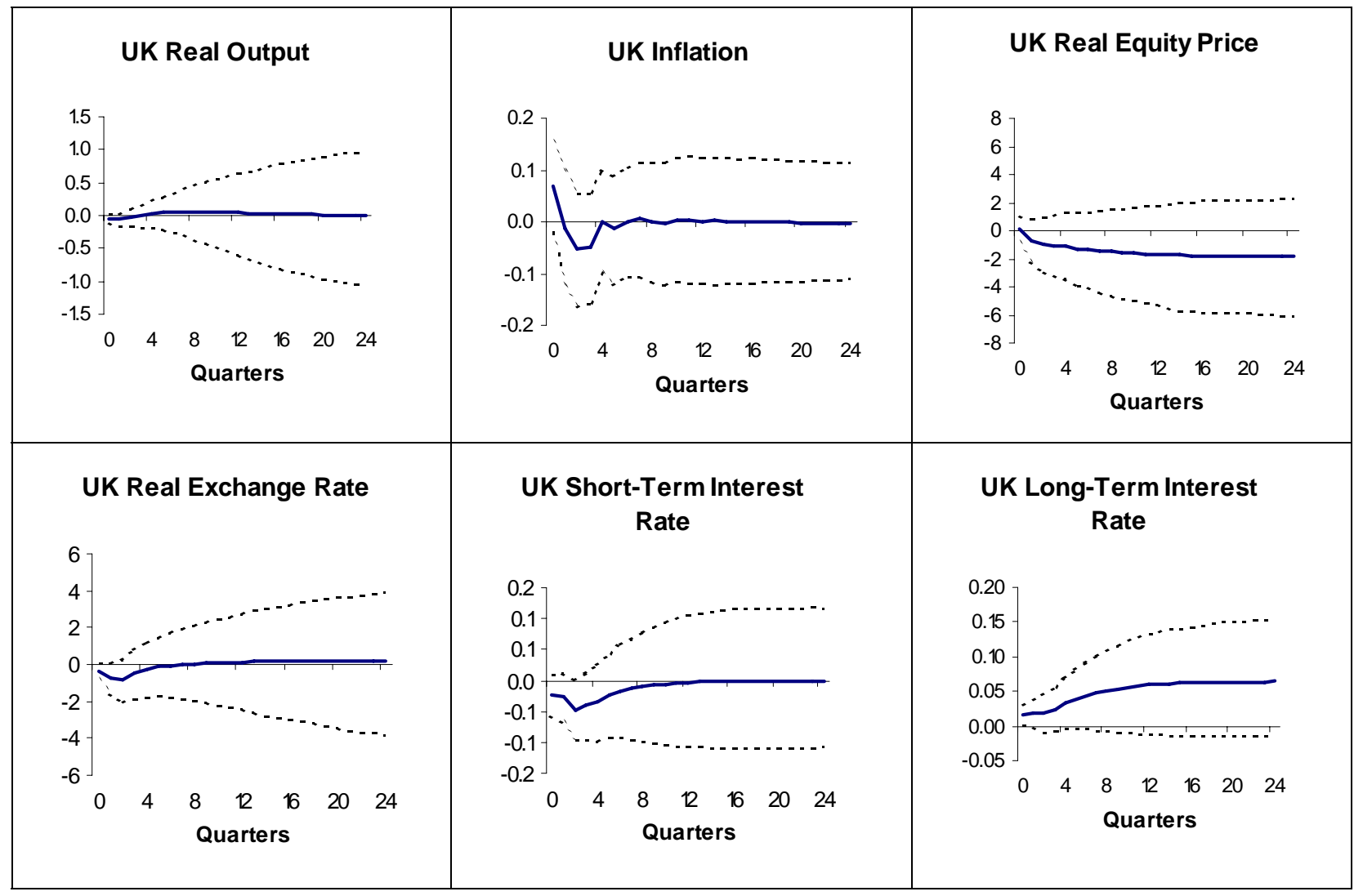

